\title{
A primer on entrustable professional activities
}

Olle ten Cate

Center for Research and Development of Education, University Medical Center Utrecht, Utrecht, The Netherlands

Entrustable professional activities (EPAs) have become a popular topic within competency-based medical education programs in many countries and hundreds of publications within only a few years. This paper was written to introduce the ins and outs of EPAs. After a brief historical overview, the rational of EPAs, as a bridge between a competency framework and daily clinical practice, is explained. Next, entrustment decision-making as a form of assessment is elaborated and framework of levels of supervision is presented. For readers interested to apply the concept in practice a stepwise approach to curriculum development is proposed. The paper concludes with an overview of the state of the art of working with EPAs in across disciplines, professions and countries.

Key Words: Clinical practice, Competency, Curriculum, Medical education, Entrustable professional activities

\section{Introduction}

Entrustable professional activities (EPAs), a new concept in medical education, has attracted much attention among medical educators. Introduced in 2005, a little over 10 years later hundreds of publications have appeared that refer to them and in many countries programs are busy incorporating EPAs. This paper is meant to introduce and explain the concept, starting with a brief historical overview.

\section{Brief historical overview}

Medicine is one of the earliest and most respected professions on earth. It has always been a highly selective and aspired career option for youth and a those holding the status of doctor, or whichever name it was given, have always been respected members of society [1]. In many societies, the right to see and treat patients, has always been restricted to well educated and trained members of a professional group, be it a university educated community, a guild with their own rules and regulations or other.

In the 19th centuries, most western countries began to regulate the medical profession on a national level, assuming responsibilities for the health of the population and to protect citizens against incompetent medical practitioners. This led to conceptions of competence, and identification of components for medical curricula. Only with the massive establishment of postgraduate training
Received: December 26, 2017 • Revised: December 26, 2017 • Accepted: January 3, 2018 Corresponding Author: Olle ten Cate (https://orcid.org/0000-0002-6379-8780)

Center for Research and Development of Education, University Medical Center Utrecht, P.O. Box \# 85500, 3508 GA Utrecht, The Netherlands

Tel: +31.88.75.57010 Fax: +31.88.75.53409 email: t.j.tencate@umcutrecht.nl

*First published in Spanish in Revista de la Fundación Educación Médica. The article was published before in FEM (FEM 2017;20(3):95-102) and that it is reproduced with the permission of FEM.
Korean J Med Educ 2018 Mar; 30(1): 1-10.

https://doi.org/10.3946/kjme.2018.76

eISSN: 2005-7288

(C) by Olle ten Cate. All rights reserved.

This is an open-access article distributed under the terms of the Creative Commons Attribution Non-Commercial License (http:// creativecommons.org/licenses/by-nc/3.0/), which permits unrestricted non-commercial use, distribution, and reproduction in any medium, provided the original work is properly cited. 
in the post World War II period and the need for definitions of educational objectives in higher education [2] outcome-based and competency-based education became an important guiding principle for medical educators [3-5]. Competency-based medical education was embraced in several countries in the 1990s and early 21 st century using frameworks to describe the breadth of the medical profession in competency terms [6-10]. Particularly for postgraduate training, professional bodies like Royal Colleges became uneasy with the model in which a fixed time in training would automatically lead to a license to practice, rather than a rigorous evaluation of the competence of the trainee. A need was felt to move from time-based to competencybased medical education [11,12]. The authoritative 2010 Carnegie Report on reform in medical school and residency also proposed fixed standards and flexible pathways [13].

While national regulators of medical training and registration of practitioners began to enforce the requirements of schools and trainees to meet these new standards, not everyone was excited. Some clinician educators [14,15] and educational scholars [16-18] voiced criticism in the literature. There was a reason to translate connect competencies better to the practice of every day work in health care.

\section{What are entrustable professional ac- tivities and why was the concept created?}

The wish to bridge this gap between well-elaborated competency frameworks and clinical practice in patient care led to the creation of EPAs [19]. EPAs are the units of professional practice that constitute what clinicians do as daily work [20]. They can be conceived of the responsibilities or tasks that must be done in patient care. These tasks can be small or big. An attending or resident on a clinical ward, called by a nurse in the night, must be able to evaluate a deteriorating patient and take action to stabilize the patient's condition. This could typically be an EPA for residency in intensive care. A junior resident in obstetrics may be entrusted with the care for a delivery if there are no signs that point at complications. A senior medical student may be asked to examine an evaluate a patient with a known chronic condition, order diagnostic test if needed, prepare follow-up medication and do all the work that only needs to be completed and signed by a clinical staff member. That can be an EPA. Even a junior medical student can contribute to health care with small but significant tasks that do not have to be checked if the student has been trained well to do them [21]. Typically EPAs are activities with a beginning and an end and are only entrusted to trained personnel. Much of any medical profession can be described in the activities the professional must be doing. What is critical in medical education at the completion of training, it that these activities can be executed safely. This means that the assessment of learners should be focused on the ability to carry these out. General competencies, such as adequate communication skills, professionalism and collaboration skills are critically important and must be evaluated, but serve to inform the key objectives of training: these professional activities.

\section{How do EPAs relate to competencies?}

EPAs constitute the description of work and are independent of persons. They operationally define a profession [19,22]. They constitute the task list each clinical department, clinical ward, or health care worker 
Table 1. EPA-Competency Matrix

\begin{tabular}{lcccccc}
\hline & EPA 1 & EPA 2 & EPA 3 & EPA 4 & EPA 5 & EPA 6 \\
\hline Medical expert & $\mathrm{xx}$ & $\mathrm{xx}$ & $\mathrm{xx}$ & $\mathrm{xx}$ & & $\mathrm{x}$ \\
Communicator & $\mathrm{xx}$ & $\mathrm{xx}$ & $\mathrm{xx}$ & $\mathrm{x}$ & $\mathrm{xx}$ & $\mathrm{xx}$ \\
Collaborator & & $\mathrm{xx}$ & $\mathrm{xx}$ & $\mathrm{xx}$ & $\mathrm{xx}$ \\
Scholar & & $\mathrm{x}$ & $\mathrm{xx}$ & & \\
Leader & & & $\mathrm{xx}$ & & $\mathrm{xx}$ \\
Health advocate & & $\mathrm{x}$ & $\mathrm{xx}$ & $\mathrm{xx}$ & $\mathrm{xx}$ \\
Professional & $\mathrm{x}$ & & & $\mathrm{xx}$ & $\mathrm{xx}$ \\
\hline
\end{tabular}

EPA: Entrustable professional activity, EPA 1: Performing a venipuncture, EPA 2: Performing an appendectomy, EPA 3: Signover at morning report after a night shift, EPA 4: Developing and implementation of a patient management plan, EPA 5: Chairing a multidisciplinary meeting, EPA 6: Requesting an organ donation, $x x$ : Competency is necessary for this EPA, $x$ : Competency is useful for this EPA.

may have for the day, for the week, or any period of time. Job descriptions can list EPAs in general terms, and task lists apply those to specific things that must occur in a plannable period of time.

Competencies describe persons. Learners who become competent professionals must acquire competencies that include knowledge, skills, and attitudes. Professionals can possess competencies; they can never possess EPAs.

EPAs and competencies (or domains of competence) can be depicted in a matrix model (Table 1). This table lists EPAs at various levels of training and maps the most important domains of competence (from the Canadian CanMEDS framework) that must be present to these EPA [23]. As is clearly visible, EPAs require multiple competencies in learners that must be applied in an integrative fashion. Even a simple task as taking a patient's history combines several domains of competence. Professionalism and communication skills are definitely necessary, but medical expertise is also indispensable to perform a focused, efficient and productive history.

\section{Entrustment decisions}

EPAs can be delegated to learners if they are deemed ready for them. The decision to transfer a responsibility to a learner has been called an entrustment decision [24]. Such decisions happen every day in the clinical environment on an ad-hoc basis. An essential component of training is the regular transfer of responsibilities, if the situation allows for it. A supervising physician does this when she feels the skills of the learner at that time match the complexity of the patient and the risks in doing this are acceptable. These are called 'ad-hoc entrustment decisions' [25]. In contrast, 'summative entrustment decisions' have the nature of certification. These are decisions taken for the future responsibilities of the learner from that moment on. In a workplace curriculum built on EPAs, summative entrustment decisions constitute the permission to carry out an EPA when there is sufficient grounding of trust among the staff, that the learner can bear this responsibility [26]. The learner is evaluated on his or her ability, and bestowed with the right and duty to be engaged in clinical service to patients [27]. While in regular programs, this right is given at the end of training, in EPA-based curricula it is given for separate EPAs at various moments throughout the program, i.e., as soon there is a justified, grounded trust that the learner has met the objectives of the program for that EPA. In this way, EPA-based curricula can be truly competencybased and not just time-based. In practice a reasonable expectation will be that most trainees meet those for all 
EPAs around graduation time, but bright students may meet them earlier, somewhat slower students later and those who combine clinical training with research, family building or other legitimate activities may also take longer. Studies however have shown that programs that deeply invest in training, simulation, supervision and frequent feedback may result is marked shortening of training [11,28].

Ad-hoc entrustment decisions, even though they happen frequently, are determined by more factors than one would think at first sight. Clinical supervisors may not always be aware of these factors, but may unconsciously weigh them in. Grouped in five, they include (1) of course the perceived learner features, (2) supervisor's propensity to delegate responsibility, (3) the complexity of the EPA, (4) the context, and (5) the nature of the relationship of the clinician and the learner [24,29-31]. Each of these can be further elaborated.

(1) Learner features include specific skills and $e^{-}$ perience with the EPA, but next to this focused ability, three other characteristics or professionalism may weigh in [27,32-34]: integrity (truthfulness in reports to a supervising clinician and benevolence), reliability (stable, predictable behavior and a conscientious way of working), and humility (the ability to observe own limitations and willingness ask for help when needed). In addition, the learner will need to know how to deal with unfamiliar situations [35].

(2) Clinical supervisors can differ vastly in how easy they delegate responsibilities to learners [24]; this is reported to depend on expertise and experience and personality [30].

(3) Clearly a more complex EPA will not be entrusted as soon to a junior learner than an easy or low-risk one. This also holds for a rare activity.

(4) The context includes the complexity of the patient, facilities that are available, the time of the day or night, the need for workforce but also the rules about supervision, working hour restrictions, and a perceived 9-5 working mentality of learners [36].

(5) The relationship between learner and supervising clinician must have evolved beyond first impressions to allow critical entrustment decisions [37,38] and it has been described as a dance that takes place between senior resident and supervising clinician when residents approach the completion of training [39].

As summative entrustment decisions have a certifying nature, sometime called a Statement of Awarded Responsibility (STAR) [19], they should be based on sufficiently grounded trust [26]. This should include an agreement between multiple observers that this entrustment is justified, to avoid subjective bias, and multiple observations. Recommended sources of information include multiple direct observations, longitudinal observations, case-based discussions, and product evaluations. In addition, scores of knowledge and skills examinations may weigh in [40].

It is important to realize that an entrustment decision implies the acceptance of risk, as it can never be fully predicted what the student will encounter. Particularly case-based discussion or entrustment-based discussion [41], short focused conversations usually after an EPA, should probe the student's deep understanding of what was done, but should include 'what-if' questions, to grasp whether the learner would know what to do what unexpected or familiar situations would arise.

\section{Levels of supervision as a scale for assessment in the workplace}

So far, we have discussed entrustment decisions related to dichotomous decisions: entrust or not yet entrust. However, it is very useful to translate entrust- 
Table 2. Entrustment and Supervision Scales: Original Form and Expanded Form

\begin{tabular}{|c|c|}
\hline $\begin{array}{l}\text { Five-level entrustment and } \\
\text { supervision scale }\end{array}$ & $\begin{array}{c}\text { Expanded entrustment and supervision scale for undergraduate and postgraduate medical } \\
\text { education }\end{array}$ \\
\hline 1. Not allowed to practice EPA & $\begin{array}{l}\text { 1. Not allowed to practice EPA } \\
\text { a. Inadequate knowledge/skill (e.g., does not know how to preserve sterile field); not allowed } \\
\text { to observe } \\
\text { b. Adequate knowledge, some skill; allowed to observe }\end{array}$ \\
\hline $\begin{array}{l}\text { 2. Allowed to practice EPA only under } \\
\text { proactive, full supervision }\end{array}$ & $\begin{array}{l}\text { 2. Allowed to practice EPA only under proactive, full supervision } \\
\text { a. As co-activity with supervisor } \\
\text { b. With supervisor in room ready to step in as needed }\end{array}$ \\
\hline $\begin{array}{l}\text { 3. Allowed to practice EPA only under } \\
\text { reactive/on-demand supervision }\end{array}$ & $\begin{array}{l}\text { 3. Allowed to practice EPA only under reactive/on-demand supervision } \\
\text { a. With supervisor immediately available, all findings and decisions double checked } \\
\text { b. With supervisor immediately available, key findings and decisions double checked } \\
\text { c. With supervisor distantly available (e.g., by phone), findings and decisions promptly } \\
\text { reviewed }\end{array}$ \\
\hline 4. Allowed to practice EPA unsupervised & $\begin{array}{l}\text { 4. Allowed to practice EPA unsupervised } \\
\text { a. With remote monitoring (e.g., next day check-in for learner questions) } \\
\text { b. Without monitoring }\end{array}$ \\
\hline $\begin{array}{l}\text { 5. Allowed to supervise others in practice } \\
\text { of EPA }\end{array}$ & 5. Allowed to supervise others in practice of EPA \\
\hline
\end{tabular}

EPA: Entrustable professional activity.

ment decisions to decreasing levels of supervision. Five main levels have been described: Level 1: the learner is allowed to be present and observe, not to enact an EPA; Level 2: the learner is allowed to execute the EPA with direct, pro-active supervision, present in the room; Level 3: the learner is allowed to carry out the EPA without a supervisor in the room, but quickly available if needed, i.e., with indirect, reactive, supervision; Level 4: the learner is allowed to work unsupervised; and Level 5: the learner is allowed to provide supervision to more junior learners. This framework has been recommended widely $[19,25,40]$. While the idea of using EPAs was created for postgraduate training programs, more recently undergraduate programs have started applying them. This has led to a more detailed framework of levels of supervision [42,43]. Table 2 shows this more detailed framework [44].

Entrustability scales as these have recently been called can have other forms [45]. In anesthesiology training such scales, translated to the 9-point scale of the mini Clinical Evaluation Exercise, proved to increase the reliability of assessment [46]. This is alike caused by a close alignment of assessment practices with clinical conversations [47]. In a recent publication Weller et al. [48] describe a 9-point entrustability scale that uses colloquial language for anesthesiology supervisors: I'm not comfortable leaving the operating room; I can take a brief coffee break; I can take a lunch break; I have to check in regularly; I can wait until asked for help; I can limit to preview everything with the trainee; I can be off site; and the trainee can work as a consultant. While is not the mainstream scale, it illustrates excellently the core idea of entrustability scales: to align assessment with clinical practice [49].

\section{Building a workplace curriculum with EPAs}

Applying EPAs in a medical curriculum can be considered a process that takes several steps [40]. 


\section{Identification of EPAs}

Describing a workplace curriculum in terms of EPAs requires a thoughtful process. EPAs as units of practice should be not too small and not too big. They are bound to working in a clinical environment. Various processes have been described to arrive at suitable EPAs, most of which involve groups of experts, locally or nationally $[22,43,50-52]$. A suitable number is 20 to $40 \mathrm{EPAs}$ for a complete program.

\section{Creating full descriptions of the EPAs}

A full EPA description includes six or seven section, and can mostly be confined to one or two pages. These sections are as follow.

1) Title

A suitable title of the activity should instantly be recognizable by clinicians and learners. It may be a noun or include a verb, but should not contain an adjective. I should not be phrased as an educational objective- it is just an activity.

\section{2) Specification and limitations}

The activity must be specified in detail and should contain no more and no less than what is exactly meant with this EPA. The specification may be a list of task components. Limitations pertain to the restriction of responsibilities of the entrustment decision, such as "only applicable with hemo-dynamically stable patients."

3) Link with the prevailing framework of competencies

The matrix of Table 1 shows EPAs require specific competencies. These can be mentioned in the third section and will guide the evaluation of task performance.

4) Required knowledge, skills, attitude, and experience that will be taken into account before a summative entrustment decision is made
5) Sources of information to support entrustment decisions

These should be a specification of satisfactory direct observations, longitudinal observations, case-based discussions, and product evaluations that should ground a summative entrustment decision.

6) Level of supervision for this EPA in this educational program that is the target

For most EPAs this may be Level 3 in medical school and Level 4 for postgraduate programs.

7) Optionally, an expiry date (or period) may be added.

This means that if, after a summative entrustment decision, the learner has not practiced the EPA for a long time, the entrustment decision may expire and the individual (learner or graduate) should be supervised again.

\section{Determining assessment frameworks and rules}

In an educational program there must be transparent rules and regulations. This may include expected moments or periods in which students or residents should meet criteria for all core EPAs. It may also include the possibility to add optional elective EPAs for bright or advanced learners.

\section{Establishment of individualized pathways with portfolios}

Competency-based medical education should allow for some flexibility and individualization in learning paths, because of differences in learner and workplace context. A program for physician assistants that is based on EPAs since 2010 found that, in this relatively short and highly individualized program, students starting out with about 7 EPAs (6.8 on average) as a target end with slight fewer completed EPAs (6.6 on average) and 1.5 altered EPAs 
over the course of this 2.5 year program, as calculated among 101 graduates [53]. A very useful approach in tracing student development and recording assessments, entrustment decisions and feedback in an electronic portfolio, several models of which are now offered commercially.

\section{Allowing for flexibility in length or breadth of training}

One burning question that often arises is how to accommodate flexibility in workplace training programs, as particularly in postgraduate training, trainees are scheduled to provide health care service and speeding up or slowing down can seriously disrupt such rotational and scheduling systems. Flexible and individualized training arrangements are the flip side of true competency-based training, but realizing this may not be easy.

There are basically two approaches. One is actually adapting schedules. In countries with a highly regulated enrolment in postgraduate programs (e.g., in the United States and Canada annually on July 1st) this may seem impossible, but in other countries students graduate from medical school at various moments across the year, and starting residency is likewise already flexible. Next, programs have possibilities to accommodate pregnancy and maternity leaves and some have combined $\mathrm{MD} / \mathrm{PhD}$ (doctor of medicine/doctor of philosophy) programs or residency/PhD programs. Those programs will not have much difficulty to incorporate competency-based flexibility.

The other approach is not to adapt the time but to distinguish core and elective EPAs and vary in the portfolio of EPAs at graduation. The Dutch Radiology Program that was redesigned to be EPA based does this. Residents are expected to add one domain of special interest to their set of core EPAs, but that could also be two or, in unusual cases, none. A supplement of Academic
Medicine in March 2018 is fully devoted to all ins and outs of competency-based time variable education.

\section{Conclusion}

EPAs were first suggested in 2005 and now have become popular among programs of postgraduate and more recently, undergraduate programs.

Specialty training psychiatry, pediatrics, internal medicine, family medicine, anesthesiology, emergency medicine, and other areas have documented [22,50,54-58]. EPAs in undergraduate medical education have become a reality in the United States [52] and in Canada [59]. Outside medicine, nursing, physician assistant training, veterinary medicine, and midwifery have been actively developing EPAs, and even such remote programs as teacher training have shown interest [60].

Specific topic such as assessment based linked to entrustment decision-making is likely to become an area of research interest and in North-America the concept of Milestones will be related to EPAs [61].

All in all, EPAs constitute an exciting new domain that has not yet developed in full but will likely affect the future of competency-based medical training in many countries [62].

ORCID:

Olle ten Cate: https://orcid.org/0000-0002-6379-8780

Acknowledgements: None.

Funding: None.

Conflicts of interest: No potential conflict of interest relevant to this article was reported. 


\section{References}

1. Lyons AS, Petrucelli RJ. Medicine: an illustrated history. New York, USA: Harry N. Abrams Inc; 1987.

2. Bloom BS, Engelhart MD, Furst EJ, Hill WH, Krathwohl DR. Taxonomy of educational objectives: the classification of educational goals: handbook $\mathrm{l}$ : cognitive domain. New York, USA: Longmans; 1956.

3. McGaghie WC, Miller GE, Sajid AW, Telder TV. Competency-based curriculum development in medical education: an introduction. Geneva, Switzerland: World Health Organization; 1978.

4. Harden RM. AMEE guide no. 14: outcome-based education: part 1-an introduction to outcome-based education. Med Teach. 1999;21(1):7-14.

5. Ten Cate O. Competency-based medical education. In: Cockerham WC, Dingwall R, Quah SR, eds. The WileyBlackwell Encyclopedia of Health, Illness, Behavior, and Society. Hoboken, USA: John Wiley \& Sons; 2014: 1329-1335.

6. CanMEDS 2000: extract from the CanMEDS 2000 Project Societal Needs Working Group report. Med Teach. 2000;22(6):549-554.

7. Swing SR. The ACGME outcome project: retrospective and prospective. Med Teach. 2007;29(7):648-654.

8. General Medical Council. Tomorrow's doctors: outcomes and standards for undergraduate medical education. London, UK: General Medical Council; 2009.

9. Pangaro L, ten Cate O. Frameworks for learner assessment in medicine: AMEE guide no. 78. Med Teach. 2013;35(6):el 197-el210.

10. Bleker OP, ten Cate J, Holdrinet RS. De algemene competenties van de medisch specialist in de toekomst [General competencies for the medical specialist in the future]. Tijdschr Med Onderwijs. 2004;23(1):4-14.

11. Long DM. Competency-based residency training: the next advance in graduate medical education. Acad Med. 2000;75(12):1178-1183.

12. Carraccio C, Wolfsthal SD, Englander R, Ferentz K, Martin C. Shifting paradigms: from Flexner to competencies. Acad Med. 2002;77(5):361-367.

13. Cooke M, Irby DM, O'Brien BC. Educating physicians: a call for reform of medical school and residency. San Francisco, USA: Jossey-Bass; 2010.

14. Brooks MA. Medical education and the tyranny of competency. Perspect Biol Med. 2009;52(1):90-102.

15. Glass JM. Competency based training is a framework for incompetence. BMJ. 2014;348:g2909.

16. Grant J. The incapacitating effects of competence: a critique. Adv Health Sci Educ Theory Pract. 1999; 4(3):271-277.

17. Hodges BD. A tea-steeping or i-Doc model for medical education? Acad Med. 2010;85(9 Suppl):S34-S44.

18. Whitehead CR, Kuper A. Faith-based medical education. Adv Health Sci Educ Theory Pract. 2017;22(1):1-3.

19. Ten Cate O, Scheele F. Competency-based postgraduate training: can we bridge the gap between theory and clinical practice? Acad Med. 2007;82(6):542-547.

20. Ten Cate O. Entrustability of professional activities and competency-based training. Med Educ. 2005;39(12): 1176-1177.

21. Chen HC, Sheu L, O'Sullivan P, ten Cate O, Teherani A. Legitimate workplace roles and activities for early learners. Med Educ. 2014;48(2):136-145.

22. Schultz K, Griffiths J, Lacasse M. The application of entrustable professional activities to inform competency decisions in a family medicine residency program. Acad Med. 2015;90(7):888-897.

23. Ten Cate O, Snell L, Carraccio C. Medical competence: the interplay between individual ability and the health care environment. Med Teach. 2010;32(8):669-675.

24. Sterkenburg A, Barach P, Kalkman C, Gielen M, ten Cate O. When do supervising physicians decide to 
entrust residents with unsupervised tasks? Acad Med. 2010;85(9):1408-1417.

25. Ten Cate O. Nuts and bolts of entrustable professional activities. J Grad Med Educ. 2013;5(1):157-158.

26. Ten Cate O, Hart D, Ankel F, et al. Entrustment decision making in clinical training. Acad Med. 2016;91(2):191198.

27. Ten Cate O. Entrustment as assessment: recognizing the ability, the right, and the duty to act. J Grad Med Educ. 2016;8(2):261-262.

28. Nousiainen MT, McQueen SA, Ferguson P, et al. Simulation for teaching orthopaedic residents in a competency-based curriculum: do the benefits justify the increased costs? Clin Orthop Relat Res. 2016;474(4): 935-944.

29. Hauer KE, ten Cate O, Boscardin C, Irby DM, Iobst W, O'Sullivan PS. Understanding trust as an essential element of trainee supervision and learning in the workplace. Adv Health Sci Educ Theory Pract. 2014; 19(3):435-456.

30. Choo KJ, Arora VM, Barach P, Johnson JK, Farnan JM. How do supervising physicians decide to entrust residents with unsupervised tasks?: a qualitative analysis. J Hosp Med. 2014;9(3):169-175.

31. Wijnen-Meijer $M$, van der Schaaf $M$, Nillesen $K$, Harendza S, Ten Cate O. Essential facets of competence that enable trust in medical graduates: a ranking study among physician educators in two countries. Perspect Med Educ. 2013;2(5-6):290-297.

32. Kennedy TJ, Regehr G, Baker GR, Lingard L. Point-ofcare assessment of medical trainee competence for independent clinical work. Acad Med. 2008;83(10 Suppl):S89-S92.

33. Mayer RC, Davis JH, Schoorman FD. An integrative model of organizational trust. Acad Manag Rev. 1995; 20(3):709-734.

34. Holzhausen Y, Maaz A, Cianciolo AT, ten Cate O, Peters
H. Applying occupational and organizational psychology theory to entrustment decision-making about trainees in health care: a conceptual model. Perspect Med Educ. 2017;6(2):119-126.

35. Wijnen-Meijer M, van der Schaaf M, Booij E, et al. An argument-based approach to the validation of UHTRUST: can we measure how recent graduates can be trusted with unfamiliar tasks? Adv Health Sci Educ Theory Pract. 2013;18(5):1009-1027.

36. Teman NR, Gauger PG, Mullan PB, Tarpley JL, Minter RM. Entrustment of general surgery residents in the operating room: factors contributing to provision of resident autonomy. J Am Coll Surg. 2014;219(4):778787.

37. Hirsh DA, Holmboe ES, ten Cate O. Time to trust: longitudinal integrated clerkships and entrustable professional activities. Acad Med. 2014;89(2):201-204.

38. Sagasser MH, Fluit CRMG, van Weel C, van der Vleuten CPM, Kramer AWM. How entrustment is informed by holistic judgments across time in a family medicine residency program: an ethnographic nonparticipant observational study. Acad Med. 2017;92(6):792-799.

39. Balmer DF, Giardino AP, Richards BF. The dance between attending physicians and senior residents as teachers and supervisors. Pediatrics. 2012;129(5):910-915.

40. Ten Cate O, Chen HC, Hoff RG, Peters H, Bok H, van der Schaaf M. Curriculum development for the workplace using Entrustable Professional Activities (EPAs): AMEE guide no. 99. Med Teach. 2015;37(11):983-1002.

41. Ten Cate O, Hoff RG. From case-based to entrustmentbased discussions. Clin Teach. 2017;14(6):385-389.

42. Chen HC, van den Broek WE, ten Cate O. The case for use of entrustable professional activities in undergraduate medical education. Acad Med. 2015;90(4):431-436.

43. Wisman-Zwarter $N$, van der Schaaf $M$, ten Cate O, Jonker G, van Klei WA, Hoff RG. Transforming the learning outcomes of anaesthesiology training into 
entrustable professional activities: a Delphi study. Eur J Anaesthesiol. 2016;33(8):559-567.

44. Peters H, Holzhausen Y, Boscardin C, ten Cate O, Chen HC. Twelve tips for the implementation of EPAs for assessment and entrustment decisions. Med Teach. 2017; 39(8):802-807.

45. Rekman J, Gofton W, Dudek N, Gofton T, Hamstra SJ. Entrustability scales: outlining their usefulness for competency-based clinical assessment. Acad Med. 2016; 91(2):186-190.

46. Weller JM, Misur M, Nicolson S, et al. Can I leave the theatre?: a key to more reliable workplace-based assessment. Br J Anaesth. 2014;112(6):1083-1091.

47. Crossley J, Johnson G, Booth J, Wade W. Good questions, good answers: construct alignment improves the performance of workplace-based assessment scales. Med Educ. 2011;45(6):560-569.

48. Weller JM, Castanelli DJ, Chen Y, Jolly B. Making robust assessments of specialist trainees' workplace performance. Br J Anaesth. 2017;118(2):207-214.

49. Kogan JR, Conforti LN, Iobst WF, Holmboe ES. Reconceptualizing variable rater assessments as both an educational and clinical care problem. Acad Med. 2014;89(5):721-727.

50. Hauer KE, Kohlwes J, Cornett P, et al. Identifying entrustable professional activities in internal medicine training. J Grad Med Educ. 2013;5(1):54-59.

51. Fessler HE, Addrizzo-Harris D, Beck JM, et al. Entrustable professional activities and curricular milestones for fellowship training in pulmonary and critical care medicine: report of a multisociety working group. Chest. 2014;146(3):813-834.

52. Englander R, Flynn T, Call S, et al. Toward defining the foundation of the MD degree: core entrustable professional activities for entering residency. Acad Med. 2016;91(10):1352-1358.

53. Wiersma F, Berkvens J, ten Cate O. Flexibility in individualized, competency-based workplace curricula with EPAs: analyzing four cohorts of physician assistants in training. Med Teach. 2017;39(5):535-539.

54. Boyce P, Spratt C, Davies M, McEvoy P. Using entrustable professional activities to guide curriculum development in psychiatry training. BMC Med Educ. 2011;11:96.

55. Englander R, Carraccio C. From theory to practice: making entrustable professional activities come to life in the context of milestones. Acad Med. 2014;89(10):13211323.

56. Jonker G, Hoff RG, ten Cate OT. A case for competencybased anaesthesiology training with entrustable professional activities: an agenda for development and research. Eur J Anaesthesiol. 2015;32(2):71-76.

57. Beeson MS, Warrington S, Bradford-Saffles A, Hart D. Entrustable professional activities: making sense of the emergency medicine milestones. J Emerg Med. 2014; 47(4):441-452.

58. Kwan J, Crampton R, Mogensen LL, Weaver R, van der Vleuten CP, Hu WC. Bridging the gap: a five stage approach for developing specialty-specific entrustable professional activities. BMC Med Educ. 2016;16:117.

59. Touchie C, Boucher A. Entrustable professional activities for the transition from medical school to residency. Ottawa, Canada: Association of Faculties of Medicine of Canada; 2016.

60. Leijen A, Slof B, Malva L, Hunt P, van Tartwijk J, van der Schaaf M. Performance-based competency requirements for student teachers and how to assess them. Int J Inf Educ Technol. 2017;7(3):190-194.

61. Nasca TJ, Philibert I, Brigham T, Flynn TC. The next GME accreditation system: rationale and benefits. $\mathrm{N}$ Engl J Med. 2012;366(11):1051-1056.

62. Touchie C, ten Cate O. The promise, perils, problems and progress of competency-based medical education. Med Educ. 2016;50(1):93-100. 